\title{
ARTICLE
}

\section{Study on restricted use of contaminated rubble on Fukushima Daiichi NPS site (1) Estimation of reference radiocesium concentration for recycling materials}

\author{
Taro Shimada*, Kazuji Miwa and Seiji Takeda \\ Japan Atomic Energy Agency, 2-4 Shirakata, Tokai-mura, Naka-gun, Ibaraki-ken, 319-1195, Japan
}

\begin{abstract}
Rubbles with less than $5 \mu \mathrm{Sv} / \mathrm{h}$ of surface dose rate, which are stored outdoor in the Fukushima Daiichi NPS (1F) site, will be recycled and applied in a restricted reuse only within the $1 \mathrm{~F}$ site in the future. In this study, we suggested a methodology for establishing the reference radioactive concentration of recycling material for the restricted reuse in the $1 \mathrm{~F}$ site. Reference radiocesium concentrations consisting of ${ }^{134} \mathrm{Cs}$ and ${ }^{137} \mathrm{Cs}$ are calculated so that increased dose rate by restricted reuse does not exceed $1 \mu \mathrm{Sv} / \mathrm{h}$ which is the minimum value of dose rate map in the $1 \mathrm{~F}$ entire site. In order to justify the restricted reuse under the reference concentration calculated, additional occupational dose, annual dose at the site boundary and groundwater concentration at the outlet to the ocean are evaluated and confirmed that the values were below $2 \mathrm{mSv} / \mathrm{y}, 1 \mathrm{~m} \mathrm{~Sv} / \mathrm{y}$ and $1 \mathrm{~Bq} / \mathrm{L}$, respectively. And then we calculated the reference radiocesium concentrations of the recycling material used for paved roads and the base of concrete building.
\end{abstract}

Keywords: Fukushima Daiichi NPS; restricted reuse; contaminated rubbles; reference radiocesium concentration; existing exposure situation

\section{Introduction}

A large amount of contaminated rubbles arising from the accident and activities toward the decommissioning is stored in the Fukushima Daiichi Nuclear Power Station (NPS) (1F) site of Tokyo Electric Power Company (TEPCO). Of the rubbles with less than $0.1 \mathrm{mSv} / \mathrm{h}$ of surface dose rate stored outdoor in the site, rubbles with less than $5 \mu \mathrm{Sv} / \mathrm{h}$ will be recycled and applied in a restricted use only within the $1 \mathrm{~F}$ site in the future [1]. The amount of the rubbles stored until 2028 is estimated to be $180,000 \mathrm{~m}^{3}$. If it is possible for the rubbles to be reused with suppressing additional exposure dose for workers in the site under the appropriate radiation control, it will contribute to reduce the amount of radioactive wastes in the future because clean materials are not brought from outside of the site. However, there is no precedent for establishing the reference values such as dose and/or concentration for reuse or recycling under the existing exposure situation. In order to appropriately introduce the restricted reuse in the $1 \mathrm{~F}$ site, technical and regulatory studies are necessary.

In this study, in order to ensure the safety regarding the reuse of the contaminated rubbles in the $1 \mathrm{~F}$ site, we suggested a methodology for establishing the reference radioactive concentration of recycling material for the restricted use in the $1 \mathrm{~F}$ site under existing exposure

*Corresponding author. Email: shimada.taro@jaea.go.jp situation, and then calculated the reference radiocesium concentrations of the recycling material used for paved roads and the bases of concrete building.

\section{Methodology for evaluation of reference concentration for restricted reuse at the $1 \mathrm{~F}$ site}

\subsection{Current status of radiation control at the $1 F$ site}

TEPCO's implementation plan approved by Nuclear Regulation Authority describes that the activities toward decommissioning of the NPS are carried out under the existing exposure situation, considering the principle of justification and the optimization [2]. In addition to the radiation controlled area and the peripheral monitoring area already introduced before the accident, the radiation management area has been introduced the same as the peripheral monitoring area, which was defined as the $1 \mathrm{~F}$ site in this paper, since the accident. All workers entering the radiation management area are regarded as occupationally exposed personnel and radiologically protected under the existing exposure situation. Maximum monthly doses of the personnel were observed from $10 \mathrm{mSv}$ to $20 \mathrm{mSv}$ in 2016 to 2017, while the average monthly doses were observed around 0.5 $\mathrm{mSv}$ [3]. The margin to the dose limit with regard to the workers with highly exposed has not been sufficient and it may be necessary to change the workers with high dose to the others with low dose not to exceed the dose limit during the decommissioning activities in the future.

The dose rates at the working environment and the 
occupational exposure doses during the work are reduced as low as reasonably achievable by introducing shielding and remote controlling available under the existing exposure situation in the $1 \mathrm{~F}$ site as the optimization of the radiation protection.

The dose rates in the entire $1 \mathrm{~F}$ site have been measured every month and the dose rate map have been disclosed through website of TEPCO. Many points of $1 \mu \mathrm{Sv} / \mathrm{h}$ were observed in the $1 \mathrm{~F}$ site other than around the reactor buildings and the storage area for absorption towers [4].

\subsection{Reference concentration under the control of worker dose}

Dose rate will be increased by reuse of recycling material from contaminated rubbles instead of clean material. On the other hand, exposure doses of all workers are controlled and the effective doses cannot exceed the occupational dose limit even though restricted reuse $(100 \mathrm{mSv}$ in five years and $50 \mathrm{mSv}$ in any single year), because the entire $1 \mathrm{~F}$ site is assigned as radiation management area under the existing exposure situation.

However, the worker for decommissioning activities may be restricted when the additional dose of individual worker increased by reuse of contaminated rubbles occupies a large part of the dose limit value. It is important to prevent increasing the dose rate by the reuse at the working environment significantly. Therefore, basic methodology for establishing reference concentration is that increased value of the dose rate by restricted reuse does not exceed the variation range of dose rates in the $1 \mathrm{~F}$ site under the existing exposure situation. The increased value of dose rate is assumed to be $1 \mu \mathrm{Sv} / \mathrm{h}$, which is the minimum dose rate observed in the entire $1 \mathrm{~F}$ site.

The reference concentration is defined for not concrete rubble itself but recycling material taken from the contaminated concrete rubbles. Based on the dose rate of $1 \mu \mathrm{Sv} / \mathrm{h}$, reference concentration is calculated for each use such as the pavement and the roadbed for road, and the base for concrete building.

\subsection{Validation of reference radiocesium concentration}

In the implementation plan, TEPCO described that the $1 \mathrm{~F}$ entire site is under the existing exposure situation and is controlled by radiation management area to protect workers and the public at the boundary of the $1 \mathrm{~F}$ site. Therefore, in order to validate the restricted reuse under the reference concentration, we take into account the actual management for workers, public and the ocean from the $1 \mathrm{~F}$ site. Figure 1 shows a methodology for evaluation of reference concentration and validation for restricted reuse at the $1 \mathrm{~F}$ site where the following three items should be confirmed.

Firstly, as described above, there is a possibility that the worker for decommissioning activities as a primary duty will be forced to reduce the working time due to reaching dose limit, when the additional dose by restricted reuse occupy a large part of dose limit. Therefore, the additional dose for worker using the recycling material should not exceed $10 \%$ of worker dose limit, $20 \mathrm{mSv} / \mathrm{y}$ considering the small margin to dose limit at current decommissioning activities in the $1 \mathrm{~F}$ site. When the evaluated worker dose under the reference radiocesium concentration exceeds the value, the concentration will be decreased to the value corresponding to $2 \mathrm{mSv} / \mathrm{y}$ of additional dose. We calculated the dose for the workers who use the material with recycling material, while the workers who take aggregates from the concrete rubbles and construct the road are outside of the scope, because the primary duty of the workers is not decommissioning but recycling for the restricted reuse and the recycling worker doses are also controlled.

Secondly, annual doses evaluated at a hundred points along the site boundary are currently controlled not to exceed $1 \mathrm{mSv} / \mathrm{y}$, taking gaseous, liquid and solid wastes originated from the $1 \mathrm{~F}$ site into account. Annual dose at the boundary will be increased by the use of recycling material. Therefore, the increased annual dose evaluated at the $1 \mathrm{~F}$ site boundary should not exceed the $1 \mathrm{mSv} / \mathrm{y}$ including the above wastes. If the recycling material is situated near the site boundary, the annual dose will exceed $1 \mathrm{mSv} / \mathrm{y}$. When the value exceeds $1 \mathrm{mSv} / \mathrm{y}$, it is

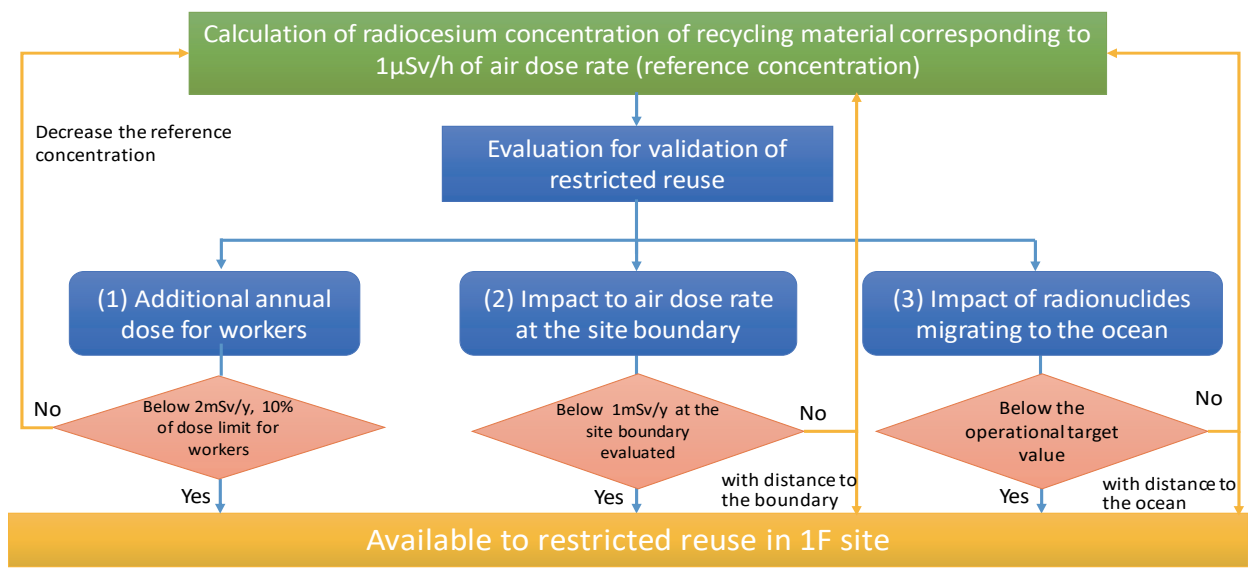

Figure 1. Methodology for evaluation of reference concentration and validation for restricted reuse at the $1 \mathrm{~F}$ site. 
also possible to evaluate the distance from the position of reuse to the boundary not to exceed the $1 \mathrm{mSv} / \mathrm{y}$.

Thirdly, when the recycling material is allocated in the soil, radionuclides migrate into groundwater by rainfall seepage. Currently, in order to compliance with the regulatory radionuclide concentration, the radionuclides concentration in groundwater discharged into the ocean are measured and controlled to the operational target of $1 \mathrm{~Bq} / \mathrm{L}$ for ${ }^{134} \mathrm{Cs}$ and ${ }^{137} \mathrm{Cs}$ by the groundwater bypass system in the $1 \mathrm{~F}$ site. Therefore, radionuclide concentration in groundwater migrating from the recycling material under the reference concentration should not exceed the operational target value. When the evaluated concentration exceeds the operational target value, it may be possible to evaluate the distance from the position of reuse to the outlet to ocean not to exceed the target concentration.

It is noted that the restricted reuse is not for unconditional release of recycling material but for conditional reuse only within the $1 \mathrm{~F}$ site. It is necessary for recycling material to be used with the information on the concentration and quantity of the recycling material and the place. Moreover, it should be considered how recycling materials applied for the restricted reuse might be dealt with as well as land soils of which surfaces were already covered with shielding when the decommissioning activities are completed and the $1 \mathrm{~F}$ site is released from the regulatory control in the future.

\section{Calculation of reference radiocesium concentration}

Based on the methodology described above, reference radiocesium concentration of recycling material from contaminated concrete rubble was calculated for each reuse and each place in the $1 \mathrm{~F}$ site. The reuse will be applied to the road constructed in the $1 \mathrm{~F}$ site, which is described in the policy [1]. Assuming that the superior quality of the aggregate taken from the concrete rubbles is ensured in the $1 \mathrm{~F}$ site, we evaluated the case with recycling material applied to base of the building, while the reuse plan is not yet described there.

\subsection{Road}

When recycling material from concrete rubbles is applied to roads in the $1 \mathrm{~F}$ site, there are two cases of pavement at the surface of the road and roadbed below the pavement. In addition, there are two kinds of pavement, asphalt and concrete [5]. Therefore, we evaluated four cases as shown in Table 1. The reference radiocesium concentrations for recycling materials taken from contaminated concrete rubbles were evaluated for paved road and bases of concrete building. Coarse aggregates are taken from the concrete rubbles and their particle-size are regulated to apply the roadbed. Crusher-run stones are manufactured by crushing concrete rubbles without particle-size regulation. In order to calculate the reference concentrations conservatively, we calculate them for crusher-run stones because a larger amount of recycling material is applied to the road.

Radiocesium is assumed to consist of ${ }^{134} \mathrm{Cs}$ and ${ }^{137} \mathrm{Cs}$, and the nuclide vector of ${ }^{134} \mathrm{Cs}$ and ${ }^{137} \mathrm{Cs}$ is 0.209 as of March 2016, based on the vector of 1 as of the accident. The dose rate at the evaluation point is calculated by gamma-ray which is released by the decay of Ba- $137 \mathrm{~m}$ originated from the decay of ${ }^{137} \mathrm{Cs}$. The possibility to decay ${ }^{137} \mathrm{Cs}$ to ${ }^{137 \mathrm{~m}} \mathrm{Ba}$ is $94.4 \%$.

The reference radiocesium concentration is calculated based on the external dose conversion factor, which is the effective dose under the reused condition of total radiocesium of $1 \mathrm{~Bq} / \mathrm{kg}$. After a concentration corresponging to $1 \mu \mathrm{Sv} / \mathrm{h}$ is calculated, the reference radiocesium concentration of recycling material is calculated by using weight mixing ratio of aggregate for each.

Table 1. Calculation cases for road materials.

\begin{tabular}{ccccc}
\hline No. & $\begin{array}{l}\text { Type of } \\
\text { pavement }\end{array}$ & Use & $\begin{array}{c}\text { Pavement } \\
\text { thickness }\end{array}$ & $\begin{array}{c}\text { Roadbed } \\
\text { thickness }\end{array}$ \\
\hline 1 & Asphalt & Roadbed & $5 \mathrm{~cm}$ & $80 \mathrm{~cm}$ \\
2 & & $\begin{array}{l}\text { Pavement } \\
20 \mathrm{~cm}\end{array}$ & - \\
3 & Concrete & $\begin{array}{l}\text { Roadbed } \\
\text { Pavement }\end{array}$ & $\begin{array}{l}15 \mathrm{~cm} \\
40 \mathrm{~cm}\end{array}$ & $80 \mathrm{~cm}$ \\
\hline
\end{tabular}

\subsubsection{Calculation condition}

Figure 2 shows the calculation geometry for the road. When the aggregates are used for pavement or roadbed of the road of which dimension is $9 \mathrm{~m}$ wide and $100 \mathrm{~m}$ long, the reference concentrations corresponding to $1 \mu$ $\mathrm{Sv} / \mathrm{h}$ at the height of $1 \mathrm{~m}$ and the center of the road are calculated. Table 2 shows the density and mixing ratio of aggregates in the pavement and roadbed. External dose conversion factor is calculated by QAD-CGGP2R [6].

Table 2. Material densities and aggregate ratios.

\begin{tabular}{lc}
\hline \multicolumn{1}{c}{ object } & value \\
\hline Concrete pavement density & $2.2 \mathrm{~g} / \mathrm{cm}^{3}$ \\
Asphalt pavement density & $2.2 \mathrm{~g} / \mathrm{cm}^{3}$ \\
Roadbed density & $2.0 \mathrm{~g} / \mathrm{cm}^{3}$ \\
$\begin{array}{l}\text { Weight mixing ratio of aggregate in } \\
\text { asphalt pavement }\end{array}$ & 0.9 \\
$\begin{array}{l}\text { Weight mixing ratio of aggregate in } \\
\text { concrete pavement }\end{array}$ & 0.8 \\
\hline
\end{tabular}

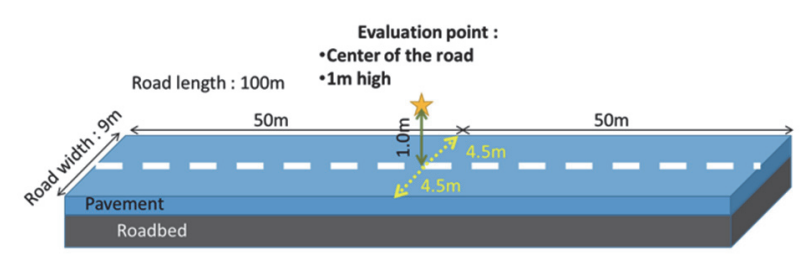

Figure 2. Calculation geometry for road materials.

\subsubsection{Calculation results}

Table 3 shows the calculated results of reference radiocesium concentrations for four cases. The concentrations were $1.0 \times 10^{5} \mathrm{~Bq} / \mathrm{kg}$ for the roadbed of concrete road as a maximum value and $7.4 \times 10^{3} \mathrm{~Bq} / \mathrm{kg}$ for the pavement of asphalt road as a minimum value. 
Table 3. Reference radiocesium concentrations for four cases.

\begin{tabular}{cccc}
\hline No. & $\begin{array}{l}\text { Type of } \\
\text { pavement }\end{array}$ & Use & $\begin{array}{c}\text { Reference radiocesium } \\
\text { concentration }(\mathrm{Bq} / \mathrm{kg})\end{array}$ \\
\hline 1 & \multirow{2}{*}{ Asphalt } & Roadbed & 13,000 \\
2 & & Pavement & 7,400 \\
3 & \multirow{2}{*}{ Concrete } & Roadbed & 100,000 \\
4 & & Pavement & 8,100 \\
\hline
\end{tabular}

\subsection{Base of building}

In order to reuse the rubbles of $180,000 \mathrm{~m}^{3}$, it is necessary to apply not only road but other utilization of recycling materials. It is assumed that a building the same as the 9th solid waste storage building will be constructed and recycling materials will be applied to the base of the building [2]. The dimension of the building is $25 \mathrm{~m}$ long, $48 \mathrm{~m}$ wide, $9 \mathrm{~m}$ high above the ground, with second basement. With reference to the drawing, the thickness of the base was set to be $2 \mathrm{~m}$.

\subsubsection{Calculation condition}

Figure 3 shows the evaluation geometry for the reuse to base of the building. The evaluation point is located at the center of the second basement floor and at the height of $1 \mathrm{~m}$. A floor slab with thickness of $0.2 \mathrm{~m}$ consisting of concrete is assumed to be situated on the base. Table 4 shows the material density and aggregate ratios in the concrete. Dose rate at the point is calculated by MCNP5 [7]. Contaminated rubbles more than $30 \mathrm{mSv} / \mathrm{h}$ of surface dose rate will be stored at the second basement.

Table 4. Material densities and aggregate ratios.

\begin{tabular}{lc}
\hline \multicolumn{1}{c}{ object } & value \\
\hline Concrete density of base & $2.1 \mathrm{~g} / \mathrm{cm}^{3}$ \\
Concrete density of floor slab & $2.1 \mathrm{~g} / \mathrm{cm}^{3}$ \\
Soil density & $1.5 \mathrm{~g} / \mathrm{cm}^{3}$ \\
Weight mixing ratio of aggregate in & 0.8 \\
base & \\
$\begin{array}{l}\text { Weight mixing ratio of aggregate in } \\
\text { floor slab }\end{array}$ & 0.8 \\
\hline
\end{tabular}

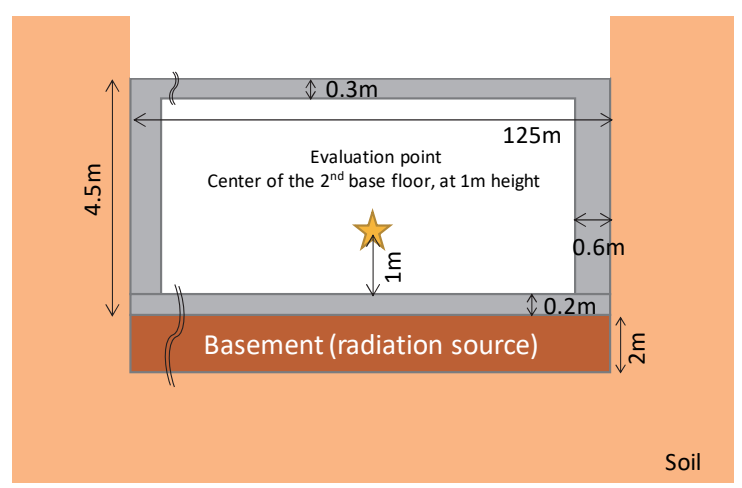

Figure 3. Calculation geometry for base of the building.

\subsubsection{Calculation results}

External dose conversion factor was calculated to $1.4 \times 10^{-5} \mu \mathrm{Sv} / \mathrm{h}$ per $\mathrm{Bq} / \mathrm{kg}$ for ${ }^{134} \mathrm{Cs}$ and $4.5 \times 10^{-6} \mu \mathrm{Sv} / \mathrm{h}$ per $\mathrm{Bq} / \mathrm{kg}$ for ${ }^{137} \mathrm{Cs}$. Therefore, the reference radiocesium concentration of recycling aggregate was
$1.6 \times 10^{5} \mathrm{~Bq} / \mathrm{kg}$ for the bases of the concrete building.

\section{Conclusion}

Rubbles with less than $5 \mu \mathrm{Sv} / \mathrm{h}$ of surface dose rate, which are stored outdoor in the Fukushima Daiichi NPS (1F) site, will be recycled and applied in a restricted reuse only within the $1 \mathrm{~F}$ site in the future. In this study, we suggested a methodology for establishing the reference radioactive concentration of recycling material for the restricted reuse under existing exposure situation in the $1 \mathrm{~F}$ site, considering with current radiation conditions. Reference radiocesium concentration is calculated so that increased dose rate by restricted reuse does not exceed $1 \mu \mathrm{Sv} / \mathrm{h}$ which is the minimum value of dose rate map in the $1 \mathrm{~F}$ entire site.

In order to justify the restricted reuse under the reference concentration calculated, we also constructed a validation methodology, considering with the current radiation management The validation methodology includes the evaluation of additional occupational dose, annual doses at the site boundary, and radiocesium concentration in groundwater at the outlet to the ocean, which should be confirmed that the values are below 2 $\mathrm{mSv} / \mathrm{y}, 1 \mathrm{mSv} / \mathrm{y}$ and $1 \mathrm{~Bq} / \mathrm{L}$, respectively.

Finally, we calculated the reference radiocesium concentrations of the recycling material used for paved roads and the bases of concrete building. As a result, the radiocesium concentrations were $1.3 \times 10^{4} \mathrm{~Bq} / \mathrm{kg}$ for the roadbed of asphalt road, $7.4 \times 10^{3} \mathrm{~Bq} / \mathrm{kg}$ for the pavement of asphalt road, $1.0 \times 10^{5} \mathrm{~Bq} / \mathrm{kg}$ for the roadbed of concrete road, $8.1 \times 10^{3} \mathrm{~Bq} / \mathrm{kg}$ for the pavement of concrete road, and $1.6 \times 10^{5} \mathrm{~Bq} / \mathrm{kg}$ for the base of the concrete building. Validation for reference radiocesium concentration calculated in this paper will be described in the paper [8].

\section{Acknowledgements}

This research is funded by the Secretariat of Nuclear Regulation Authority, Nuclear Regulation Authority, Japan.

\section{References}

[1] TEPCO, Outline of plan for storage management and renewal methods in Fukushima Daiichi NPS, Handout-1 of the 5th Committee on Radioactive Waste Issues of the Specified Nuclear Facilities of Nuclear Regulatory Authority Japan, Feb. 10, 2017, (2017). [in Japanese]

[2] TEPCO, Implementation Plan for Specific Nuclear Facilities, (2017). [in Japanese]

[3] TEPCO, Outline of Occupational Dose in Fukushima Daiichi NPS, Oct. 12, 2017, (2017). [in Japanese]

[4] TEPCO, Initiatives for improving the working environment in the Fukushima Daiichi Nuclear Power Plant, Good Practices in Radiation 
Exposure Control at the Fukushima Daiichi NPP, Nov. 10, 2015, (2015).

[5] T. Sawaguchi, S. Takeda, H. Kimura and T. Tanaka, Estimation of doses from radioactively contaminated disaster wastes reused for pavements, Jpn. J. Health Phys. 50 (1) (2015), pp.36-49. [in Japanese]

[6] Y. Sakamoto and S. Tanaka, QAD-CGGP2 and G33-GP2: Revised versions of QAD-CGGP and G33-GP, Japan Atomic Energy Research Institute
(JAERI), JAERI-M90-110 (1990).

[7] X-5 Monte Carlo Team, MCNP - A General N-Particle Transport Code, Version 5, LA-UR-03-1987 (2003).

[8] K. Miwa, T. Shimada and S. Takeda, Study on restricted use of contaminated rubble on Fukushima Daiichi NPS site (2) Validation of reference radiocesium concentration for recycling materials, Progress in Nuclear Science and Technology. (2018). [submitted] 